\title{
Bicentric conurbation and its territorial development
}

\author{
L. Teslíková Hurdálková \& D. Kutá \\ Faculty of Civil Engineering, Department of Urban Engineering, \\ Technical University of Ostrava (VSB-TUO), Czech Republic
}

\begin{abstract}
The bicentric conurbation formed now by two regional cities, Hradec Králové and Pardubice, was a significant industrial and farming region of Eastern Bohemia from 1986 to 2000 . The development of this conurbation was regulated by the Territorial Plan for the Large Territorial Unit Hradec Králové - Pardubice regional conurbation which was approved in 1989. The urbanistic conception of the entire territory was designed with an outlook for 2000. Anticipated development of industry and agriculture, including housing development pointed out to increased demands on transport and engineering infrastructure. The proposal was supported by increased demands on urbanistic development with increased demands on dwelling, civic amenities and on industrial and agricultural production. After 2000, significant transformation of primary and secondary into higher civic amenities, i.e. so far the tertiary bicentric regional Hradec Králové - Pardubice conurbation was formed by the main centres, Hradec Králové - the regional city and Pardubice, the district city. This transformation results from proclaiming Pardubice the capital of the region. In the present, the Territorial Development Policy of the Czech Republic is the superior document for development of both regions.

Keywords: bicentric conurbation, core area, territorial development, tertiary, territorial development policy, urbanistic conception, territorial development principles, Hradec Králové, Pardubice, Czech Republic.
\end{abstract}

\section{Introduction}

The territorial development of the bicentric regional conurbation Hradec Králové - Pardubice was regulated significantly by processing of the Large Territorial Unit 
Hradec Králové - Pardubice regional conurbation [1] and its external regional zone along with parts of territorial plans for Hradec Králové and Pardubice residential systems that were approved by the Government Decree of the Czech Socialist Republic on 18 May 1988. This decree included binding and directive parts. The main tasks involved ensuring other degrees of territorial planning documentation and management within the framework of development in the conurbation and residential systems in compliance with territorial plans, followed by the preparation of medium-term plans for the needs of development until 2000 and last but not least, ensuring the processing of changes and amendments to the territorial plan of the conurbation in compliance with the determination of D11 motorway section route (Prague - Hradec Králové) and the delimitation of a locality for a nuclear power station.

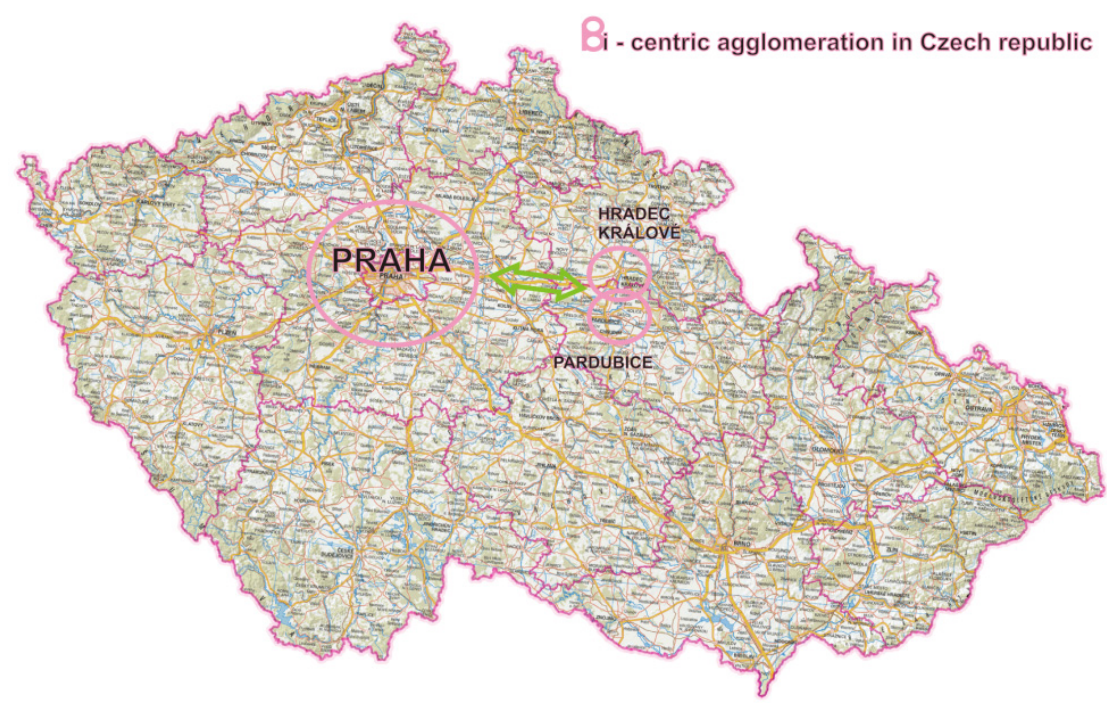

Figure 1: The location of the bicentric conurbation on the territory of the Czech Republic (source: author, background data from WMS service provided by www.cuzk.cz, 04/2015).

The basic conception of the Territorial Plan for the Large Territorial Unit Hradec Králové - Pardubice regional conurbation honoured the urbanistic development principles in compliance with needs of agricultural and industrial production with provision of viable developing projects for machinery, chemical, electrical engineering and energy industries. The quality of farmland and the reduction of airborne and waterborne pollution were followed with the subsequent development, including the elimination of adverse impacts of noise and vibrations along with creation of ecological stability. The growth of population and concentration of higher civic amenities in conurbation cores, including the related centres can be considered as the main activities in the economic development. 
The following general principles were defined when fulfilling the conception of functional utilization:

- To direct the concentrated housing development and higher civic amenities primarily to the core area of the conurbation and to Cherubim.

- To solve consistently and implement gradually the reconstruction of obsolete and functionally substandard parts in the conurbation cores, related settlement centres, and in the settlement centres of provincial importance.

- To increase the economy of urbanistic utilization of the territory and the civic amenities in them and services of supralocal importance.

- To develop industrial and storage areas following only the existing industrial and storage areas of conurbation cores and higher-type of settlement centres, following the power station area in Chvaletice and Pardubice in link with the Opatovice power station area.

- To utilize appropriately all the suitable areas allocated in the solved territory for daily and short-time recreation.

The principles defined in this way were essential for both centres since the global conception was built on equal development of centres of local importance and on the structure of their settlement, including the development of transport and engineering infrastructure.

\section{Territorial prognosis of bicentric conurbation after 2002}

The Territorial Prognosis of the Hradec Králové - Pardubice Conurbation Core Area (hereinafter TP HPCCA) was assigned for processing by the Pardubice Region, after the selection procedure, to Atelier T-plan, s.r.o. and the main cooperative company AURS s.r.o. in September 2002. The TP HPCCA was assigned as a supplemental co-ordinating document focused on the hinterland of the core cities and namely on their intermedia into which the territorial development is concentrated.

Also this conception material continued following the priorities defined in the Hradec Králové - Pardubice conurbation [1]. The significant item of this conception was the variant solution of the transport system coming out of the verification of D11 (Prague - Hradec Králové) motorway position. Owing to geographic proximity, it is possible to consider both regional cities as the capital regional centre (or bicentre) of the Eastern Bohemia area. However, the links of both cities to their wider surroundings do not overlap significantly; they do not always correspond to the administrative division (region) because Hradec Králové is nearer to some settlements in the Pardubice Region and it is also more accessible due to the layout of transport networks. Pursuant to submitted variants, the "V4 directed development" variant was chosen as it was characteristic by insertion of a new transport axis of the west-east direction (D11 and R35). In road transport, it will undoubtedly mean that some of the development activities are directed to this corridor or to its proximity. It will be of common interest for both cities. The northern continuation of D11/R11 route at the border with Poland will influence primarily the Hradec Králové sub-area more significantly. Thanks to establishing 


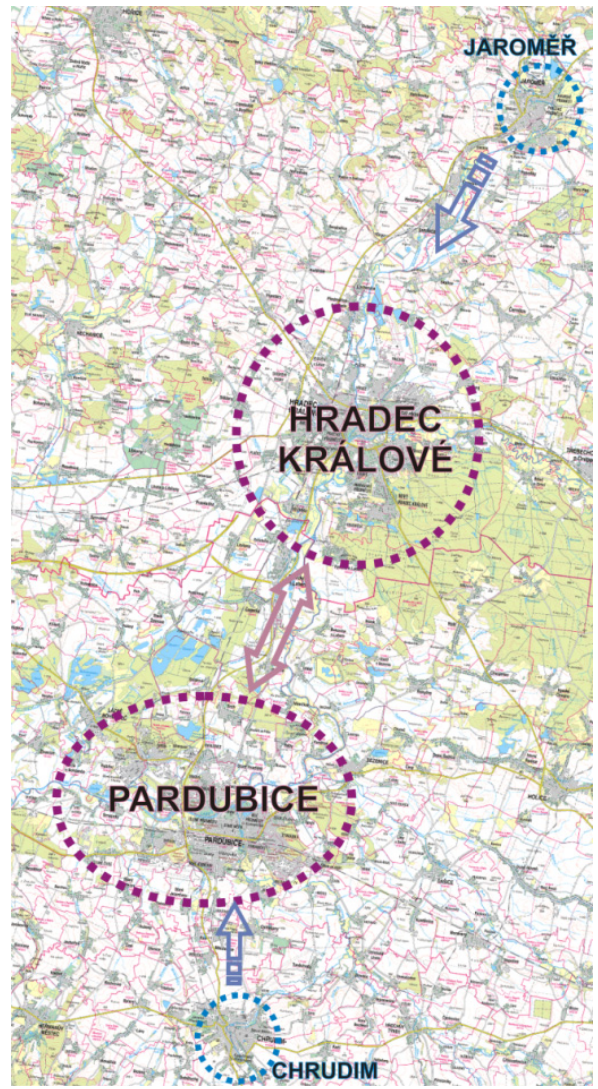

Figure 2: Core cities and their significant lower centres (source: author, background material, WMS service, www.cuzk.cz).

significant transport routes, it was anticipated that development areas would be situated near to the transit corridors which should have instigated the creation of new job offers along with mutually interconnected transport system involved in commuting to work. The V4 variant anticipated the development of Hradec Králové and Pardubice, combining the utilization of proactive development axes with other directions of development in the hinterland of the core cities. The Pardubice surroundings offer optional development in five directions: Bohdaneč, Srch, Sezemice, Chrudim, Přelouč. The city of Hradec Králové has the following development options in its hinterland: western development towards D11 by local tertiary road (LTR) Kukleny, LTR Plotiště n.L.), south of Opatovice n. L., Vysoká n. L. , the northern direction to Jaroměr̆ and the eastern one to Třebechovice p. O. (it varies in functional utilization, the rate of utilisation intensity, and the attractiveness). Apart from the transport system, the HPCCA prognosis dealt also with the development of industry and engineering infrastructure, including the population development up to 2050. Considering the growth of developing 
localities in both core centres, an increase in natural energy was expected by an increase of supply terminals but not by building the nuclear power station as it was indicated in the conception of Hradec Králové - Pardubice conurbation [1].

The idea of a decrease in the intensity of urbanization of core cities and the core intermedium will enable the proportional development of the other urban and rural urbanistic units and the utilization of natural potential for dwelling, recreation and surroundings without disturbing the economic activities. For preservation of permanent territorial separation of urbanistic structure of core cities, the important role is played the proposal for implementation of the suburban recreational landscape area: at the axis of Bohdaneč spa - sand pits Oplatil - Kunětická hora Dříteč - Hradec Králové city woods. On the left bank of the Elbe, in the area of Dříteč, EOP sludge bed (in the HK - PA intermedium), the planning of development projects adequate to a lower rate of urbanization is in contrast with intensive utilization of the right bank of the Elbe river. The suburban recreational landscape area is currently linked with another integrating phenomenon of the entire HPCCA that forms bottom lands of the Elbe, the Chrudimka and the Orlice rivers.

The creation of a common landscape-recreational area with successive activities in service sphere and in dwelling, can be a significant element linking the interests of both regional cities in creation of a harmoniously formed environment of the fourth largest concentration of population and economic activities in the Czech Republic.

The population development in V4 - directed development variant came out of territorial-engineering and social-economic conditions of the core area of the Hradec-Pardubice conurbation divided, in terms of the most suitable utilization of given and anticipated conditions, into individual function zones with recommended regulations, namely for some of them, where the interests of administrative authorities (regional, district and communal ones) and civic communities in their directed development are anticipated:

- The core territories of both regional cities, defined according to urbanistic aspects, will be subject to conversion and reconstruction according to the approved territorial plans of both statutory cities with the fact that the population development will result in a more significant development of building of low-floor and medium-floor houses within the range making it possible to decelerate the population decrease with a tendency towards stabilization until the forecasting period of 2050.

- The zone of flood-plains of the most important rivers (the Elbe, the Orlice and the Doubravka), defined according to flood lines establishes a territory with anticipated tightening of regulations for a new build-up area so that, apart from current more or less uncontrolled development (population growth 300 inhabitants, i.e. by 7\%), a fundamental reduction of residential functions should occur by 2050 (by approx. by $30 \%$, i.e. by 1,300 inhabitants).

- The suburban residential areas, namely those lying in the intermedia, have already become bearers of new housing development and consequently also the population development of the core area -the suggested development is 
consistent with the development as per V1 variant - concentric one, following both the existing trends and respecting the interests and needs of the inhabitants living in both regional cities.

- The zones with supremacy of production and storage areas and other economic activities, existing and perspective ones - namely at motorway crossroads are focused, as indicated by their names, on other functions than residential ones and on adverse factors - noise generated by transport and activities, dust nuisance and harmful exhaust emissions from traffic and activities and others lead to the regulation of new build-up area in the given zones - a decrease in population by 1600 , i.e. by $20 \%$ is proposed by 2050 .

- Specialized zones reserved for supra-local sports and recreational activities, incl. the proposed regional recreational park Oplatil are the least populated of all urbanistic zones for territorial utilization and no new residential development is expected in them except for purposeful service development. Only after the end of service life of the existing sludge beds for fly-ash in the area of Dříteč - Borek - Zástava, a moderate growth is possible - by 100 inhabitants (i.e. by $20 \%$ ) by 2050 .

- The zones of natural character formed mostly by continuous and more extensive forests with minor and scattered settlement are very attractive though - namely in view of future individual housing, but that is where the administrative restriction is recommended for this demand along with the application of construction-engineering regulations so that the natural character of these zones, forming the necessary hinterland of both cities and smaller centres, cannot be diminished or fragmented. So the outlook for 2050 recommends steady stabilization of settlement at the level achieved (moderate increase by 300 inhabitants, i.e. by $12 \%$ ).

- The zone of farming country, with the largest surface area, includes tens of minor (and several medium-sized) country houses found largely on outskirts of the core area but also in the intermedia. The above mentioned fundamental turn in the development of this long-term depopulating territory is also in compliance with the plans for the development of this zone but contrary to Variant 1, it is in somewhat moderate form, requiring less expensive need for a new engineering infrastructure. By 2050, a moderate population growth is proposed - for the entire zone approx. by $20 \%$ (by 2000 inhabitants) in total. In its summary, the V4 directed development suggests stabilization and moderate gradual turn in the existing population-adverse development being expressed by subsequent total number of inhabitants of the core area per stages (thousands of inhabitants).

Pursuant to evaluation of the suitability of general conception, the Hradec Králové - Pardubice conurbation [1] and the HPCCA, the proposed functional areas and their selection for the assumed forward-looking functions, it seems that it would be a mistake if the unique territorial and urbanistic conditions of the core intermedia of the conurbation are not utilized and if the purposeful co-operation and certain distribution of functions between both cities with populations of 100 thousand are not implemented in terms of achieving the effectiveness of investments invested in future. For sustainable territorial development, it is 
evidently more acceptable to regulate and direct the desirable development of a thoughtfully designed agglomerated urbanistic unit with 300 thousand inhabitants in comparison with the development of two rival conurbations having approx. 150 thousand inhabitants each.

\section{Co-ordination of territorial development of the conurbation after 2008}

Since 2008 when the Ministry of Regional Development issued the national conception document for territorial development, the Spatial Development Policy of the Czech Republic [1] has been the main instrument for territorial planning on the whole territory of the Czech Republic, defining the requirements for instantiation of territorial planning tasks related to inland, border and outland context with reference to sustainable development of the territory. The definition of development axes and regions on the territories where international and domestic activities are concentrated resulted in localization of increased requirements for changes within the territory. Development areas defined in this way include the municipalities influenced by the development dynamics of the main centre, by both centres (regional cities) in this case. Siting of the bicentric regional conurbation in the OB4 development area constituted significant development of transport infrastructure in particular.

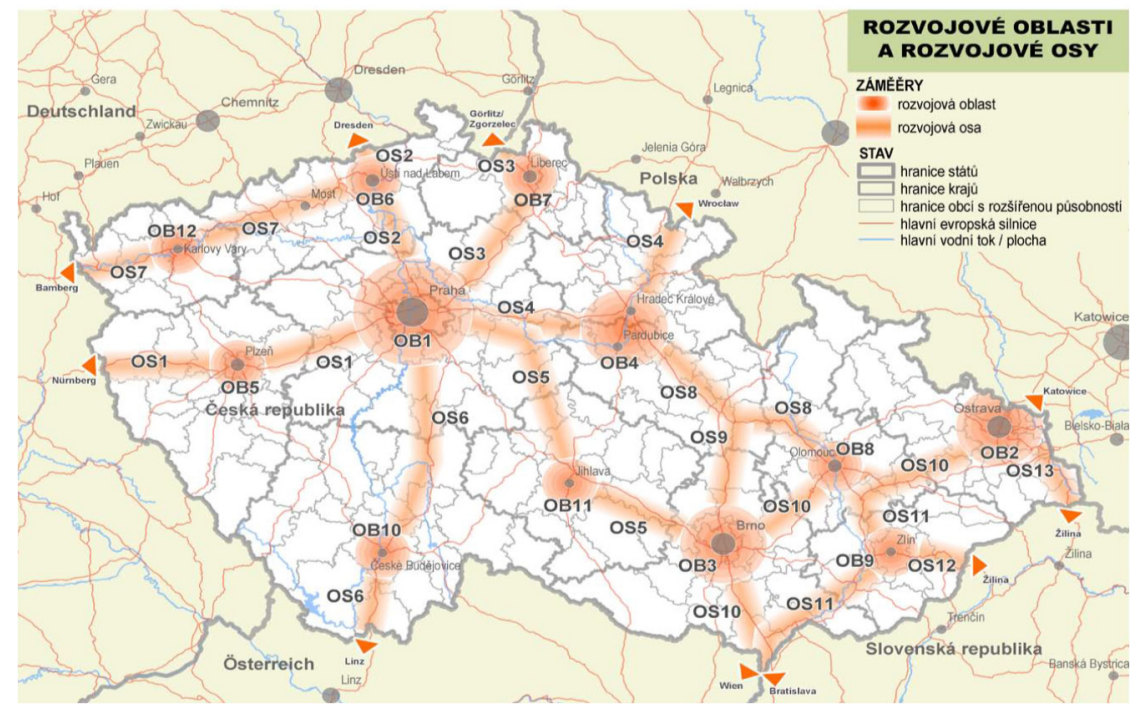

Figure 3: Delimitation of development areas and development axes on the territory of the Czech Republic in the Spatial Development Policy of the Czech Republic [1].

Since 2009, work on principles of territorial development of the Hradec Králové [3] and Pardubice regions 0 . These conception papers did not deal with 
the core area of the bicentric conurbation more deeply, they only co-ordinated the intentions from the Spatial Development Policy of the Czech Republic [1] and of individual territorial plans in their administrative territories. A closer and more detailed specification of the development for the conurbation was not implemented. In 2014, after more than 10 years since the HPCCA 0, the development strategy of Integrated Territorial Investments for the Hradec Králové - Pardubice metropolitan area [5] came into existence. This conception document points at the results of previous conception materials for the Hradec - Pardubice conurbation territory and it simultaneously extends the solved territory pursuant to commuting to regional centres. Non-implemented plans and considerations on territorial development of the Hradec Králové - Pardubice conurbation are only supplemented in relation to the extended territory. This strategy does not suggest new solutions of the territorial development for the HPCCA territory.

\section{Conclusions}

Nowadays, the development of transport infrastructure (completion of D11 motorway enables the connection Prague - Hradec Králové - Jaroměř, R35 highway will improve the road link between Liberec region and Moravia and R11 will enable the border link with Poland) in connection with international road and motorway network that is the main tendency of development as such. An open question so far remains the subject matter of restoration of fragments of extinct fish ponds from the historical fish pond system as accumulation reservoirs of flood control importance.

\section{Acknowledgement}

The work was supported by the Student Grant Competition VSB-TUO, under project registration number SP2015/165.

\section{References}

[1] Hradecko - pardubická aglomerace (ÚPN, draft 1989), approved by the Czechoslovak government on 18. 5. 1989, TERPLAN - National Bureau of Urban Planning, 1989, archive of the Regional Council of the Hradec Králové Region (KÚ KHK)

[2] Ministry of Regional Development, Institute for Spatial Development, Spatial Development Policy of the Czech Republic 2008, 07/2009. Available at: http://www.mmr.cz/cs/Stavebni-rad-a-bytova-politika/Uzemni-planovani-astavebni-rad/Koncepce-Strategie/Politika-uzemniho-rozvoje-Ceskerepubliky

[3] SURPMO a.s. Principles of regional development of Hradec Králové region - November 2011. Available at: http://www.kr-kralovehradecky.cz/rozvojkraje/uzemni-planovani/zasady-uzemniho-rozvoje-kralovehradeckeho-kraje$46187 /$ 
Körner, Milan et al. Principles of territorial development of Pardubice region - Legal situation after update No. 1 October 2014. Prague: AURS, spol s.r.o., 2014. Available at: http://www.pardubickykraj.cz/zasady-uzemniho-rozvoje

[4] Territorial prognosis of the Hradec Králové - Pardubice conurbation core territory, Atelier T-plan, s.r.o., AURS, s.r.o., 03/2003

[5] Strategy of integrated territorial investment for Hradec Králové - Pardubice metropolitan area 2014, Regional Development Agency of Pardubice region, GAREP, spol. s.r.o., 08/2014 